\title{
On implicit racial prejudice against infants
}

\author{
Lukas J. Wolf, ${ }^{1}$ Gregory R. Maio, ${ }^{1}$ Johan C. Karremans, ${ }^{2}$ \\ and Caroline Leygue ${ }^{3}$
}

Group Processes \& Intergroup Relations 2017, Vol. 20(6) 789-800 (C) The Author(s) 2016

\section{(C) $(1) \Theta$ \\ Reprints and permissions: sagepub.co.uk/journalsPermissions.nav DOI: $10.1177 / 1368430216629812$ journals.sagepub.com/home/gpi}

@SAGE

\begin{abstract}
Because of the innocence and dependence of children, it would be reassuring to believe that implicit racial prejudice against out-group children is lower than implicit prejudice against out-group adults. Yet, prior research has not directly tested whether or not adults exhibit less spontaneous prejudice toward child targets than adult targets. Three studies addressed this issue, contrasting adults with very young child targets. Studies 1A and B revealed that participants belonging to an ethnic majority group (White Europeans) showed greater spontaneous favorability toward their ethnic in-group than toward an ethnic out-group (South Asians), and this prejudice emerged equally for infant and adult targets. Study 2 found that this pattern occurred even when race was not a salient dimension of categorization in the implicit measure. Thus, there was a robust preference for in-group children over out-group children, and there was no evidence that this prejudice is weaker than that exhibited toward adults.
\end{abstract}

\section{Keywords}

ageism, children, implicit, out-group, prejudice

Paper received 9 December 2014; revised version accepted 26 October 2015.

Around the world, children frequently appear in campaigns to elicit donations for victims of famine, disease, and natural disaster (e.g., UNICEF Ireland, 2011). Similarly, to receive more money from passers-by, beggars often bring their children to the streets in a pitiful state (Rachel, 1989). The implicit assumption may be that, compared to adults, children elicit greater sympathy (Rachel, 1989), helping to short-circuit any negative sentiments, which can be egregious when the individuals being helped are members of other ethnic, religious, or national groups (Dovidio, Kawakami, \& Gaertner, 2002; McConnell \& Leibold, 2001). Indeed, children appear frequently in campaigns against prejudice (e.g., Ligue Internationale Contre le Racisme et l'Antisémitisme, 2010; National Fair Housing Alliance, n.d.). Thus, whether it is an appeal for donations to help people in impoverished nations or a campaign against

\footnotetext{
${ }^{1}$ Cardiff University, UK

${ }^{2}$ Radboud University Nijmegen, The Netherlands

${ }^{3}$ University of Nottingham, UK

Corresponding author:

Lukas J. Wolf, School of Psychology, Cardiff University, 70 Park Place, Cardiff CF10 3AT, UK.

Email:wolflj@cardiff.ac.uk
} 
racism, children are often used to elicit sympathy and potentially combat prejudice.

This use of child targets broadly fits evidence that children are seen as innocent and in need of protection (Goff, Jackson, Di Leone, Culotta, \& DiTomasso, 2014; Lampinen \& Sexton-Radek, 2010). In a similar vein, adults with more neonatal facial features (e.g., large eyes, small chin; Berry \& McArthur, 1985) have been shown to be perceived as warmer, kinder, and more honest than adults with less neonatal facial features (Berry \& McArthur, 1985; McArthur \& Apatow, 1984), and it has been found that neonatal facial features elicit protective behaviors and motivations for caretaking (Alley, 1983; Glocker et al., 2009). As a result, children belonging to an ethnic out-group may be seen more positively than out-group adults. But do we actually exhibit less prejudice against out-group children than against adults? That is, could the preference for the in-group over the out-group be weaker for children than for adults? Even if children per se elicit more positive responses, regardless of their group membership, it could still be the case that ingroup children are preferred to out-group children. This preference could remain even though attitudes to both child groups are more positive than attitudes to both adult groups. Indirect support for the prediction that prejudice may also play a role comes from research showing that Afrocentric facial features may spontaneously trigger prejudicial responses. Specifically, Blair, Judd, and Chapleau (2004) found that prison inmates with more Afrocentric facial features received harsher sentences than those with less Afrocentric facial features and that the judges were unaware of this influence. This finding fits the view that facial features typical for a negatively perceived group may lead to a spontaneous activation of the stereotypes and prejudice associated with that group. If out-group features are also visible in neonatal faces, then child out-group members' facial features may spontaneously elicit a prejudiced response, short-circuiting any emotional mechanisms related to the elicitation of sympathy in child targets. Consequently, the relative roles of out-group features and neonatal features are difficult to prefigure. Do they coexist independently from each other and exert a similar influence on evaluations and behaviors or does one counteract the influence of the other?

There is provocative evidence that partially addresses this question and suggests that outgroup features may play a more important role than child features. For example, in a study by Goff et al. (2014), White participants indicated that when the criminal suspects were Black children they saw them as less innocent, more culpable, and as older than when the criminal suspects were White children. Importantly, this appeared only to be the case for targets who were 10 years or older. For younger targets, participants did not perceive a difference in innocence between Black and White children. Moreover, the extent to which participants evaluated Black children as less innocent and older than White children was predicted by how strongly they dehumanized Black people on an implicit measure, but not by their explicit or implicit prejudice. Hence, although this study shows that out-group features play a dominant role in the perception of outgroup children's innocence, this only seemed to apply to older children. Moreover, in an earlier study, Downey and Pribesh (2004) showed that White teachers, as compared to Black teachers, rated Black kindergartners and eighth graders as displaying poorer classroom behavior than their White fellow students. This indicates that outgroup members become victims of prejudice already at a very early age. In a similar vein, Baron and Banaji (2006) presented child and adult participants with self-report measures of prejudice and an implicit measure of prejudice against child targets. Results indicated that prejudice decreased with age of the participant on an explicit selfreport measure, whereas the implicit preference for in-group children over out-group children was similarly strong within 6 -year-olds, 10 -yearolds, and adults. This study has drawn attention to the presence of prejudice in children and the way in which spontaneous prejudice (as assessed in the implicit measures) is maintained at adulthood while explicit self-reports of prejudice decrease. Nonetheless, all of these studies leave 
unanswered the question of whether or not adults exhibit less prejudice toward child targets than toward adult targets, because the studies did not test whether prejudice toward out-group children significantly differed from prejudice directed toward out-group adults.

To address this issue, the present research tested whether adults' spontaneous racial bias toward children differs from their spontaneous racial bias toward adults. We focused on spontaneous racial bias, as opposed to deliberative, selfreport measures of bias, partly because of limitations in the ability of the latter measures to detect prejudice. The high social undesirability of admitting racial prejudice, which should be even more undesirable in the case of child targets, makes it unlikely that explicit measures of prejudice will be sensitive to the existence of prejudice against racial and child targets. At the same time, obtaining knowledge about adults' spontaneous racial bias is important because it may influence many behaviors toward out-group children, including small behavioral slights with large ramifications (e.g., dismissiveness, exclusion). Such subtle, spontaneous victimization of out-group children may be one of the hardest forms of prejudice to detect, especially in settings where the children's parents cannot witness the subtle slights they may receive from other adults (e.g., in schools, shops, sports clubs). Moreover, adults cannot always be there to help the children interpret, and cope with, their situations.

We conducted three studies (1A, 1B, and 2) examining spontaneous prejudice against both child and adult targets. The studies selected White European participants, who constitute the majority group in the United Kingdom, where the research was conducted. We recruited participants belonging to the racial majority group because spontaneous in-group preferences have been demonstrated reliably for such groups, whereas the spontaneous preferences of racial minority group members are more varied (Nosek, Banaji, \& Greenwald, 2002; Rudman, Feinberg, \& Fairchild, 2002). We used White European ingroup and South Asian out-group targets, because people of South Asian (e.g., Indian, Pakistani,
Bangladeshi) descent are the largest racial minority group in the United Kingdom (Office for National Statistics, 2012). In addition, we included very young children as targets (i.e., babies, toddlers). Previous research showed that younger children were perceived as more innocent than older children, and equally so for in-group and out-group children (Goff et al., 2014). Moreover, we selected very young children as targets to ensure that the facial characteristics were quite distinct from those of adults. To robustly examine implicit prejudice, the studies also included different sets of images, different variants of the implicit measure, relevant control variables (e.g., facial attractiveness), and potential moderators (i.e., implicit attitude to children per se).

Based on previous research, which showed that racial prejudice against children does exist (Baron \& Banaji, 2006; Downey \& Pribesh, 2004), we hypothesized that racial prejudice would be evidenced for both infant and adult targets. It therefore seemed likely that participants' spontaneous racial prejudice would not be attenuated for child targets, compared to adult targets. Nonetheless, the mixed theory and evidence reviewed in the previous lines left us initially agnostic on this latter question.

\section{Study 1A}

Study 1A examined whether spontaneous racial prejudice is lower toward children than toward adults. Participants were presented with pictures and names of children or adults from the ingroup and from the out-group within the Implicit Association Test (IAT; Greenwald, McGhee, \& Schwartz, 1998). Baron and Banaji (2006) had presented this test using faces of four Black children and four White children substituted for faces of Black adults and White adults. In a similar way, we assessed participants' spontaneous favorability toward our four subgroups: South Asian infants, European White infants, South Asian adults, and European White adults. We used two commonly employed types of IATs. One IAT used pictures of South Asian and European White targets, and the other IAT used 
South Asian names and European White names. The use of both methods enabled us to test for convergence of the conclusions across both procedures. As described before, we expected that participants would exhibit spontaneous racial prejudice toward adult and child targets.

\section{Method}

Participants and procedure. One hundred and thirteen psychology students (112 women; 18-48 years, $M=19.61$ years) of White European descent took part for course credit at Cardiff University. One hundred and nine participants selfidentified as British and four participants self-identified as Eastern European. We excluded three participants of Asian descent, but the same effects were obtained when these participants were included in the analyses.

When participants arrived in the lab, they completed an image-based South AsianEuropean White IAT followed by a name-based South Asian-European White IAT. Either participants saw images and then names of South Asian and European White infants or they saw images and then names of South Asian and European White adults. This ordering ensured that children were salient during both the childfocused, image-based IAT and the child-focused, name-based IAT. Hence, for both IATs in combination, participants were randomly assigned to the between-participants conditions of child targets or adult targets.

LATs. The two race IATs presented six positively and six negatively valenced words (e.g., love, fun, war, hate). The first, image-based, IAT employed eight photos of infant targets and eight photos of adult targets. In the second, name-based, IAT, the pictures were replaced with eight common South Asian or White European names. Both IATs comprised three practice blocks containing 20 trials each and two test blocks containing 40 trials each. In these trials, participants viewed the valenced words and pictures or names in the middle of the screen and identified them by race (i.e., Asian vs. White) or by valence (i.e., positive vs. negative), depending on the trial. Response times to the test blocks were used to compute D-scores for each participant (Greenwald, Nosek, \& Banaji, 2003), such that higher scores indicated less prejudice.

Child target condition. In the child target condition, the eight images in the image-based IAT included two pictures of White European babies, two pictures of South Asian babies (gender unclear), one picture of a White European male toddler, one picture of a South Asian male toddler, one picture of a White European female toddler, and another of a South Asian female toddler.

In the name-based IAT, four of the eight names were traditional Indian names (e.g., Raj, Kavita) and four were traditional British names (e.g., Chris, Jennifer). Participants were first given the eight names and told that they were names of children from a maternity ward. They were asked to indicate for each name whether it refers to an Asian or a White child. Also, as mentioned previously, we chose to present the image-based IAT before the name-based IAT in order to make it easier for participants to imagine child targets.

Adult target condition. In the image-based IAT, the eight images included two pictures of South Asian men, South Asian women, White European men, and White European women. For the name-based IAT, participants in the adult condition were simply given the list of names and asked to indicate whether they refer to an Asian or a White person.

\section{Results}

Past research has repeatedly found significant racial bias in the IAT (Dovidio et al., 2002; Greenwald et al., 1998; McConnell \& Leibold, 2001). Consistent with this evidence, a one-sample $t$ test on the image-based IAT showed that the participants' mean D-score across age conditions deviated significantly from zero $(M=-0.51$, $S E=0.03), t(112)=-16.02, p<.001$, Cohen's $d=-1.51$. This pattern reflects more positivity 
toward White Europeans than South Asians. The mean D-score deviated significantly from zero for pictures of adults $(M=-0.56, S E=0.04)$, $t(54)=-14.88, p<.001$, Cohen's $d=-2.01$, and for pictures of infants $(M=-0.46, S E=0.05)$, $t(57)=-9.20, p<.001$, Cohen's $d=-1.21$. Moreover, the effect sizes were large in both cases, and there was no significant difference between the $\mathrm{D}$-scores for infants and adults, $t(111)=-1.56, p=.12$, Cohen's $d=-0.15$. Hence, for both images of adults and infants, participants exhibited more spontaneous favorability toward White Europeans than South Asians.

For the name-based IAT, a one-sample $t$ test showed that participants' mean D-score was significantly below zero $(M=-0.51, S E=0.03)$, $t(112)=-15.14, p<.001$, Cohen's $d=-1.42$. This result again reveals more positivity to White Europeans than South Asians. As in the imagebased IAT, participants' D-score deviated significantly from zero for adults $(M=-0.52$, $S E=0.05), t(54)=-9.90, p<.001$, Cohen's $d=-1.33$, and infants, $(M=-0.51, S E=0.04)$, $t(57)=-11.54, p<.001$, Cohen's $d=-1.52$. There was no significant difference between the D-scores for infants and adults, $t(111)=0.09$, $p=.92$, Cohen's $d=0.01$, and, as shown before, there were large effect sizes for both age groups. Hence, for adult and infant targets, participants showed more spontaneous favorability toward White Europeans than South Asians. ${ }^{1}$

\section{Discussion}

In line with our expectations, Study $1 \mathrm{~A}$ found strong evidence of spontaneous racial prejudice even when the targets were infants. That is, White Europeans showed a spontaneous preference for their racial in-group over a South Asian minority out-group for both children and adults. These results were obtained regardless of whether the stimuli were images or words.

\section{Study 1B}

Study 1B used largely the same sample of participants as Study 1A (see Participants and Design section in the following lines), because Study 1A and $1 \mathrm{~B}$ were appended to two different sessions of another, irrelevant study (with $1 \mathrm{~A}$ in the first session and $1 \mathrm{~B}$ in the second). Study $1 \mathrm{~B}$ was designed to address several issues that were salient after Study 1A. First, we wanted to examine the replicability of the findings of Study 1A using different photos, thereby assessing implicit prejudice using a third set of stimuli differing from the two sets used in Study 1A. Second, although Cunningham, Preacher, and Banaji (2001) demonstrated the stability of IAT effects for adult targets, we knew of no data examining the stability of IAT effects for child targets. Hence, we wished to assess the stability of people's spontaneous attitudes toward outgroup children versus in-group children. Third, we explored whether the racial bias toward child targets would be eliminated in people with more positive spontaneous attitudes to children. Thus, we tested whether individual differences in spontaneous attitude to children moderated the strength of the racial bias. Finally, in order to assess any preexisting differences between pictures in the imagebased IAT, participants rated all pictures on happiness and attractiveness.

Overall, we expected that the spontaneous race bias that was obtained in Study $1 \mathrm{~A}$ regardless of the target's age would replicate and prove stable over time. Moreover, we hypothesized that the spontaneous race bias would occur irrespective of the rated happiness and attractiveness of the targets.

\section{Method}

Participants. Three weeks after Study 1A, 104 participants from Study 1A (103 women; 18-48 years, $M=19.66$ years) took part in this study at Cardiff University for course credit. The participants were of White European descent: 99 participants self-identified as British and four participants self-identified as Eastern European. We excluded three participants of Asian descent, but the principal results were unchanged by their inclusion in the analyses.

For a number of reasons, we assumed that using largely the same sample in Study 1A and 1B 
would not lead to carry-over effects or raised suspicions about the study's purpose among participants. That is, because Study 1A was appended to a first session and Study 1B to a second session of another study, participants were not fully debriefed at the end of Study $1 \mathrm{~A}$ and only expected to receive a debrief at the end of Study 1B. Moreover, Study 1B occurred 3 weeks after Study $1 \mathrm{~A}$, it was presented as a new study without any mention of Study $1 \mathrm{~A}$, and Study $1 \mathrm{~A}$ and $1 \mathrm{~B}$ both formed part of a larger set of tests. Hence, we assumed that participants were naïve about the purpose of Study 1B and that they were unlikely to be influenced by their prior performance in Study 1A. Participants' feedback during our funnel-style debriefing supported these assumptions.

Procedure. Participants first completed an imagebased Race IAT similar to that used in Study 1A, with either infant or adult targets. The only change was that we included eight more pictures of infant targets and eight more pictures of adult targets. Thus, in total, participants in the child condition were repeatedly presented with eight pictures of White European infants (two male and two female toddlers, four babies) and eight pictures of South Asian infants (two male and two female toddlers, four babies), whereas participants in the adult condition were repeatedly presented with eight pictures of White European adults (four women, four men) and eight pictures of South Asian adults (four women, four men).

The subsequent task was an IAT that implicitly assessed participants' attitude toward children versus adults in general. This measure was adopted from past research (Leygue, Maio, Gebauer, Karremans, \& Webb, 2013) and was the same for all participants. This IAT possessed the same general structure as the Race IAT, but it presented words denoting the child category (e.g., toddler, baby) or the adult category (e.g., grown-up, adult) and positive or negative words. Participants classified the stimuli according to their age category or valence on each trial. D-scores were calculated for both IATs, as in Study 1A.
Finally, participants rated the pictures they saw in the image-based IAT on happiness and attractiveness. These ratings were made using 7-point scales from 1 (not at all) to 7 (very much).

\section{Results}

Replication of Study $1 \mathrm{~A}$. As in Study $1 \mathrm{~A}$, a onesample $t$ test across conditions on $\mathrm{D}$-scores from the image-based IAT was significant $(M=-0.48$, $S E=0.04), t(103)=-11.67, p<.001$, Cohen's $d=-1.14$. The direction of this effect indicates that participants exhibited more spontaneous favorability toward White Europeans than South Asians. Moreover, this effect was present for adult targets $(M=-0.52, S E=0.04), t(50)=$ $-11.51, p<.001$, Cohen's $d=-1.61$, and for infant targets, $(M=-0.44, S E=0.07), t(52)=$ $-6.48, p<.001$, Cohen's $d=-0.89$. There was no significant difference between $\mathrm{D}$-scores for infant and adult targets, $t(102)=-0.99, p=.32$, Cohen's $d=-0.10$, and the effect sizes were again large for both age groups. These results replicate the findings of Study 1A, using an expanded set of stimuli in the IATs.

Correlation between Study $1 A$ and $1 B$. To address the stability of IAT effects for child targets, we examined the correlation between $\mathrm{D}$-scores on the image-based IATs from Studies 1A and 1B. This correlation revealed that the spontaneous racial bias toward child targets was moderately stable over 3 weeks, $r(51)=.52, p<.001$. Unexpectedly, the correlation was nonsignificant in the subsample that was presented with adult targets, $r(51)=.17, p=.24$.

Role of implicit child attitude. To address the third aim of this study, we entered target age (child vs. adult; dummy coded), centered child-adult IAT scores, and their interaction as predictors of the IAT D-scores. This analysis revealed no significant effects for target age, $t(100)=1.01, p=.31$, $\beta=.10$, nor child-adult IAT scores, $t(100)=1.25$, $p=.21, \beta=.13$. More relevant, there was no significant interaction, $t(100)=-0.72, p=.47$, $\beta=-.07$. Thus, spontaneous attitudes to children 
in general did not moderate spontaneous racial prejudice to child versus adult targets.

Picture ratings. To examine differences in target attractiveness and happiness, we first conducted a 2 (target age: children vs. adults) x 2 (target race: White European vs. South Asian) mixedmodel MANOVA on the attractiveness and happiness of the presented targets. This analysis revealed a significant main effect of target age on attractiveness, $F(1,102)=24.31, p<.001$, $\eta^{2}=.19$. The child targets were seen as more attractive $(M=4.68, S E=0.11)$ than the adult targets $(M=3.91, S E=0.11)$. The effect of target age on happiness was not significant, $F(1,102)=0.60, p=.44, \eta^{2}=.01$.

The main effect of target race was significant both for attractiveness and for happiness, $F(1,102)$ $=14.46, p<.001, \eta^{2}=.12 ; F(1,102)=20.97$, $p<.001, \eta^{2}=.17$. Specifically, White European targets were seen as more attractive $(M=4.45$, $S E=0.09)$ and happier $(M=4.61, S E=0.06)$ than South Asian targets $(M=4.15, S E=0.09$; $M=4.36, S E=0.07)$. The interaction between target race and target age was not significant for attractiveness, $F(1,102)=0.00, p=.95, \eta^{2}=.00$, but it was significant for happiness, $F(1,102)=35.84$, $p<.001, \eta^{2}=.26$. The simple effects of target age indicated that, for adults, White European targets were seen as happier $(M=4.73, S E=0.09)$ than South Asian targets $(M=4.15, S E=0.10), F(1,50)$ $=50.75, p<.001, \eta^{2}=.50$. Of importance, this effect was nonsignificant for child targets, $F(1,52)$ $=1.09, p=.30, \eta^{2}=.02$.

Correction for picture ratings. It is plausible that the perceived difference in attractiveness between the White European and South Asian child targets is itself an indirect indicator of prejudice. Nonetheless, it was important to test whether the perception of greater attractiveness for the White European child targets than South Asian child targets was necessary to detect the Race IAT effect. To address this issue, we conducted a regression analysis with the algebraic difference between rated South Asian and White European child attractiveness as a predictor of the child
Race IAT effects. This analysis revealed that participants who rated the South Asian child targets as more attractive also revealed more spontaneous positivity toward them, $t(51)=2.23$, $p=.03, \beta=.30$. More important, the intercept remained significant, $t(51)=-5.67, p<.001$, Cohen's $d=-0.80$, showing that the South Asian-White European child attractiveness ratings could not account for the child D-scores' significant deviation from zero. Another way of illustrating this is by examining the mean D-scores among those who rated the South Asian child images as more attractive than the White European child images. Even in this group, the $\mathrm{D}$-scores were still negative and significantly different from zero, $t(24)=-2.70, p=$ .013 , Cohen's $d=-0.54$. Thus, differences in perceived target attractiveness are not sufficient to account for the spontaneous bias.

\section{Discussion}

With an expanded set of stimuli, we replicated White Europeans' spontaneous preference for their in-group over a South Asian minority outgroup, even when the targets were infants. As in Study 1A, implicit prejudice was not attenuated for children. Second, participants' spontaneous prejudice was stable over time for child targets; hence, spontaneous prejudice against infants was again easy to detect and stable. Third, the results indicated that implicit prejudice was unaffected by whether participants spontaneously liked children or not, suggesting that evaluations of race in children are substantively different from judgments of children. Fourth, it is noteworthy that the spontaneous racial bias directed toward children emerged even though the White European and South Asian children were seen as being equally happy, and differences in perceived attractiveness of the children were unable to account for the spontaneous racial bias. Overall, then, the spontaneous racial bias against children was replicable, stable over time within individuals, unrelated to spontaneous attitudes toward children, and not explained by perceived differences in target happiness and attractiveness. 


\section{Study 2}

The evidence so far indicates a robust spontaneous racial bias, even when the targets are infants. However, it is conceivable that the relative salience of race plays a role in producing this IAT effect. That is, individuals can often be classified according to multiple categories (e.g., race, gender, age) at the same time, and research indicates that evaluations depend on which category is most salient (Crisp \& Turner, 2011; Mitchell, Nosek, \& Banaji, 2003). For instance, the targets' race may have been more salient than the targets' age in the Race IATs in Studies $1 \mathrm{~A}$ and 1B because participants were asked to classify individuals in one of two racial categories, and this may have caused race bias to dominate in spontaneous responses. To circumvent the potential role of category salience in IAT effects, Study 2 used Single-Target IATs (ST-IATs), which examine the absolute spontaneous favorability toward a single group without contrasting it against another (Bluemke \& Friese, 2008; Dotsch \& Wigboldus, 2008). For example, by presenting South Asian children against no other target group, spontaneous responses can be driven by ethnicity, age, or both without constraint from the task. This way, it is possible to examine the interplay between race and age more directly and independently of the potential influence of category salience.

Moreover, Study 2 addressed another potential issue. Specifically, one potential factor behind IAT effects is the category labeling and not the individual stimuli (de Houwer, 2001). Hence, if participants only considered the categories "Asian" and "White," but not the adult or child stimuli, it would be unsurprising that we only found an effect of race and not of age. However, studies have shown that, if stimuli are unitarily atypical for the respective category (e.g., positively viewed Blacks), participants redefine the category and the IAT race effect is eliminated (Govan \& Williams, 2004). Therefore, participants in Study 1A and 1B should have redefined the categories in the child IAT as "South Asian children" and "White European children" and shown a reduced IAT effect, if children are indeed unitarily positive. Nevertheless, in Study 2 we addressed this issue more directly with the ST-IATs, which allow us to eliminate the influence of category labels because the only target category label that participants view is "Faces" (see Materials section in what follows). Thus, any effects on the ST-IATs should be driven by participants' spontaneously constructed categories based on the individual stimuli. Overall, we hypothesized, based on the findings in Study 1A and $1 \mathrm{~B}$, that participants would show spontaneous racial bias, regardless of the target's age.

\section{Method}

Participants and design. For this study, we selected a new sample of 88 psychology students (78 women; $18-26$ years, $M=19.21$ years) from Cardiff University who took part for course credit. We excluded one participant of Asian descent, but the results were unchanged by including this person. The remaining participants were of White European descent. Participants were randomly assigned to complete ST-IATs for either White European or South Asian targets, with the age of these targets (child vs. adult) manipulated within-subjects.

Procedure. Participants completed two ST-IATs in counterbalanced order. Participants in the White European condition completed an ST-IAT assessing their spontaneous attitude toward White European infants and another ST-IAT assessing their spontaneous attitude toward White European adults. In contrast, participants in the South Asian condition completed an STIAT that assessed their spontaneous attitude toward South Asian infants and another ST-IAT that assessed their spontaneous attitude toward South Asian adults. This design was intended to make age the only salient difference between the ST-IATs, thereby introducing more potential for the race bias to be reduced, especially for younger targets.

Materials. The ST-IATs used the same pictures and words as the IATs in Study 1B. The White 
European and the South Asian infant target groups each consisted of two male and two female toddlers and of four babies, whereas the White European and the South Asian adult target groups each consisted of four men and four women. Each ST-IAT consisted of three blocks of trials in total. The first block, the practice block, involved 16 trials of classifying adjectives as either positive or negative. The test blocks consisted of 36 trials each. In one of the test blocks, participants classified positive words and pictures showing the respective category (i.e., White European infants, White European adults, South Asian infants, or South Asian adults) with one key and negative words with another key. In the other test block, participants classified negative words and pictures showing the respective category with one key and positive words with another key. Better performance on the former block than on the latter block is assumed to reflect positive associations with the tested category (Bluemke \& Friese, 2008; Dotsch \& Wigboldus, 2008). In the test blocks, participants were only asked to categorize faces in addition to the evaluative words, so that no particular category (e.g., South Asian children) was made salient in the instruction. The order of the test blocks was counterbalanced. The results of the ST-IAT were examined using D-scores.

\section{Results}

A 2 (age of target) x 2 (race of target) mixedmodel ANOVA was conducted on participants' ST-IAT D-scores, with target age as the withinparticipants factor and target race as the betweenparticipants factor. This analysis yielded a nonsignificant main effect of target age, $F(1,86)$ $=1.13, p=.29, \eta^{2}=.01$, but a marginally significant effect of target race, $F(1,86)=3.43, p=.07$, $\eta^{2}=.04$. Specifically, participants had a tendency to exhibit more spontaneous favorability toward White European targets $(M=0.18, S E=0.04)$ than toward South Asian targets $(M=0.07, S E=$ 0.04). The one-sample $t$ tests for each target group revealed significant positivity to White European infants $(M=0.24, S E=0.04), t(41)=$ $5.69, p<.001$, Cohen's $d=0.88$, and marginally significant positivity to White European adults $(M=0.11, S E=0.05), t(41)=1.99, p=.053$, Cohen's $d=0.31$. In contrast, D-scores did not deviate significantly from zero for both South Asian infants $(M=0.06, S E=0.05), t(45)=1.17$, $p=.25$, Cohen's $d=0.17$, and South Asian adults $(M=0.09, S E=0.06), t(45)=1.38, p=.17$, Cohen's $d=0.20$.

Crucially, the interaction was nonsignificant, $F(1,86)=2.15, p=.15, \eta^{2}=.02$. Thus, the greater favorability to White European than South Asian targets was equally evident for adult and very young child targets. ${ }^{2}$

\section{Discussion}

White European participants again showed more spontaneous favorability toward their in-group than toward a South Asian minority out-group, even when the targets were infants. Even though this effect was marginal $(p<.07)$, we are confident in interpreting it because of our a priori hypotheses and the consistency with Studies $1 \mathrm{~A}$ and $1 \mathrm{~B}$. Furthermore, it is interesting that this effect of race emerged even though we deliberately made age the only characteristic distinguishing the two ST-IATs that participants received, which should have made age more salient than race. In addition, participants showed this race effect although they were not presented with race category labels. Hence, participants used these race categories spontaneously based on the individual stimuli.

A useful feature of ST-IATs is that they are well suited to detecting differences between ingroup favorability and out-group derogation. In this regard, it is interesting that, similar to other studies of implicit prejudice (e.g., Karpinski \& Steinman, 2006), the preference for White Europeans over South Asians was driven by spontaneous in-group favorability, whereas the spontaneous attitude toward the out-group was neutral. More important, this pattern was at least as strong for infant targets as it was for adult targets. Thus, Study 2 suggests that the robust spontaneous racial bias toward children among the majority group members (i.e., White Europeans) 
emerges because of robust in-group favoritism, rather than persistent out-group derogation.

\section{General Discussion}

To our knowledge, the present research provided the first direct comparison of spontaneous racial prejudice against child targets versus adult targets. Contrary to the notion that greater sympathy toward child targets than toward adult targets short-circuits prejudice against children, results revealed greater spontaneous favorability among majority group members to their racial in-group over a racial out-group even when the targets were infants. This effect occurred across different sets of verbal and pictorial stimuli and different implicit measures. Furthermore, the results of Study 2 revealed the locus of the effect; that is, the spontaneous racial bias is more attributable to robust in-group favoritism than to outgroup derogation. Together, these findings challenge the notion that prejudice against children is lower than prejudice against adults; spontaneous racial in-group bias is strong among majority group members even when very young targets are considered.

Why is the spontaneous race bias so prevalent? On the one hand, it would seem to be at odds with perspectives that stress social learning and stereotypes in prejudice (Devine, 1989; Ehrlich, 1973): the babies in our sample of targets were too young to be viewed as conforming to common stereotypes. In the time constraints imposed by the IATs, it also seems unlikely that people might spontaneously reimagine children in the future. In addition, it is difficult to explain the results in terms of a general negativity bias, wherein our judgments tend to be more strongly influenced by negative items of information than by positive items of information (e.g., Baumeister, Bratslavsky, Finkenauer, \& Vohs, 2001; Ito, Larsen, Smith, \& Cacioppo, 1998). Study 2 showed that spontaneous prejudice toward child targets was more consistent with a difference resulting from in-group favorability than with a spontaneously negative response to the outgroup racial category. Thus, the pattern suggests that the prevalence of spontaneous racial bias may be connected to a latent bias in favor of ingroup characteristics (e.g., skin color).

This possibility is important because, as explained in the Introduction, racial biases against children may lead to subtle, spontaneous victimization (e.g., dismissiveness, exclusion) which is difficult to detect and difficult to cope with for the children. However, if the racial biases against children stem more from a lack of positive responses to out-group targets, then the effects on out-group children may be even more difficult to notice and counteract than if subtle negative reactions were evident.

We hope that future research will address the inevitable limitations of our first foray into this issue. For instance, our research samples included a bias toward female participants. Whereas Leygue et al. (2013) did not find any gender differences in spontaneous preference for children over adults, other research has shown that women report a stronger wish for a child, which may suggest that they are explicitly more positive toward children (Stöbel-Richter, Beutel, Fink, \& Brähler, 2005). Moreover, Nosek et al. (2002) found that women reveal a lower spontaneous racial bias than men. Notwithstanding our finding that the racial bias was equally present across male and female adults and children (see Endnote 1), the extant research may suggest that racial prejudice toward children would, if anything, be even higher in a participant sample including more men. A replication with a more gender-balanced sample would help to further test the robustness and generalizability of the present findings.

In addition, although the present research provides a consistent demonstration of spontaneous racial prejudice among a sample of majority group members (i.e., White Europeans in the UK), it would be useful to examine spontaneous prejudice among minority group members. Research has shown that people's spontaneous preference for their racial in-group can be lower or even favor the majority group if the minority group's status in society is lower (Nosek et al., 2002; Rudman et al., 2002). Hence, it would be fruitful to examine whether racial minority group 
members show a similar spontaneous racial bias for both children and adults. Furthermore, the extent and direction of racial bias may depend on a range of other situational and individual factors. For example, it would be beneficial to test whether kindergarten teachers show the same amount of spontaneous racial bias toward children and adults. Future research could examine such effects using additional racial and ethnic groups beyond those included in our studies.

Notwithstanding this need for further research, the present evidence makes clear that we cannot idealistically assume that people are any less prejudiced toward infants from ethnic out-groups than they are to older members of the ethnic out-groups. Although we might hope that youth elicits more sympathy, race looms large in spontaneous reactions.

\section{Funding}

The author(s) received no financial support for the research, authorship, and/or publication of this article.

\section{Notes}

1. Based on Nosek et al.'s (2002) findings that female targets are spontaneously preferred over male targets, we conducted supplementary analyses in Study 1A, 1B, and 2 to test whether racial prejudice would be attenuated for female targets relative to male targets. Only Study 1B showed a moderation effect, such that racial prejudice was lower for male targets than for female targets, contrary to our expectations. Across the three tests, we did not find consistent evidence that spontaneous racial bias is dependent on the target's gender.

2. For exploratory purposes, we also examined whether a spontaneous preference for female targets over male targets, as shown by Nosek et al. (2002), could be attenuated for child targets compared to adult targets. In a 2 (target gender: male vs. female) x 2 (target age: child vs. adult) repeated measures ANOVA, the main effects of gender and age were nonsignificant, $F(86)=1.99, p=$ $.16, \eta^{2}=.02 ; F(86)=1.14, p=.29, \eta^{2}=.01$. Their interaction was also nonsignificant, $F(86)=0.46$, $p=.50, \eta^{2}=.01$. Hence, there was no spontaneous gender bias and this did not interact with the target's age.

\section{References}

Alley, T. R. (1983). Infantile head shape as an elicitor of adult protection. Merrill-Palmer Quarterly, 29, 411-427.

Baron, A., \& Banaji, M. (2006). The development of implicit attitudes: Evidence of race evaluations from ages 6 and 10 and adulthood. Psychological Science, 17, 53-58. doi:10.1111/j.14679280.2005.01664.x

Baumeister, R. F., Bratslavsky, E., Finkenauer, C., \& Vohs, K. D. (2001). Bad is stronger than good. Review of General Psychology, 5, 323-370. doi:10.1037/1089- 2680.5.4.323

Berry, D. S., \& McArthur, L. Z. (1985). Some components and consequences of a babyface. Journal of Personality and Social Psychology, 48, 312-323. doi:10.1037/0022-3514.48.2.312

Blair, I. V., Judd, C. M., \& Chapleau, K. M. (2004). The influence of Afrocentric facial features in criminal sentencing. Psychological Science, 15, 674-679. doi:10.1111/j.0956-7976.2004.00739.x

Bluemke, M., \& Friese, M. (2008). Reliability and validity of the Single-Target IAT (ST-IAT): Assessing automatic affect towards multiple attitude objects. European Journal of Social Psychology, 38, 977-997. doi:10.1002/ejsp.487

Crisp, R. J., \& Turner, R. N. (2011). Cognitive adaptation to the experience of social and cultural diversity. Psychological Bulletin, 137, 242-266. doi:10.1037/a0021840

Cunningham, W. A., Preacher, K. J., \& Banaji, M. R. (2001). Implicit attitude measures: Consistency, stability and convergent validity. Psychological Science, 12, 163-170. doi:10.1111/1467-9280.00328

De Houwer, J. (2001). A structural and process analysis of the Implicit Association Test. Journal of Experimental Social Psychology, 37, 443-451. doi:10.1006/ jesp.2000.1464

Devine, P. G. (1989). Stereotypes and prejudice: Their automatic and controlled components. Journal of Personality and Social Psychology, 56, 5-18. doi:10.1037/0022-3514.56.1.5

Dotsch, R., \& Wigboldus, D. H. J. (2008). Virtual prejudice. Journal of Experimental Social Psychology, 44, 1194-1198. doi:10.1016/j.jesp.2008.03.003

Dovidio, J. F., Kawakami, K., \& Gaertner, S. L. (2002). Implicit and explicit prejudice and interracial interaction. Journal of Personality and Social Psychology, 82, 62-68. doi:10.1037/0022-3514.82.1.62

Downey, D., \& Pribesh, S. (2004). When race matters: 'Teachers' evaluations of students' classroom 
behavior. Sociology of Education, 77, 267-282. doi:10.1177/003804070407700401

Ehrlich, H. J. (1973). The social psychology of prejudice. New York, NY: Wiley.

Glocker, M. L., Langleben, D. D., Ruparel, K., Loughead, J. W., Gur, R. C., \& Sachser, N. (2009) Baby schema in infant faces induces cuteness perception and motivation for caretaking in adults. Ethology, 115, 257-263. doi:10.1111/j.14390310.2008.01603.x

Goff, P. A., Jackson, M. C., Di Leone, B. A. L., Culotta, C. M., \& DiTomasso, N. A. (2014). The essence of innocence: Consequences of dehumanizing Black children. Journal of Personality and Social Psychology, 106, 526-545. doi:10.1037/a0035663

Govan, C. L., \& Williams, K. D. (2004). Reversing or eliminating IAT effects by changing the affective valence of the stimulus items. Journal of Experimental Social Psychology, 40, 357-365. doi:10.1016/j. jesp.2003.07.002

Greenwald, A. G., McGhee, D. E., \& Schwartz, J. L. K. (1998). Measuring individual differences in implicit cognition: The Implicit Association Test. Journal of Personality and Social Psychology, 74, 1464-1480. doi:10.1037/0022-3514.74.6.1464

Greenwald, A. G., Nosek, B. A., \& Banaji, M. R. (2003). Understanding and using the Implicit Association Test: I. An improved scoring algorithm. Journal of Personality and Social Psychology, 85, 197-216. doi:10.1037/0022-3514.85.2.197

Ito, T. A., Larsen, J. T., Smith, N. K., \& Cacioppo, J. T. (1998). Negative information weighs more heavily on the brain: The negativity bias in evaluative categorizations. Journal of Personality and Social Psychology, 75, 887-900. doi:10.1037/0022-3514.75.4.887

Karpinski, A., \& Steinman, R. B. (2006). The single category Implicit Association Test as a measure of implicit social cognition. Journal of Personality and Social Psychology, 91, 16-32. doi:10.1037/00223514.91.1.16

Lampinen, J. M., \& Sexton-Radek, K. (2010). Protecting children from violence: Historical roots and emerging trends. In J. M. Lampinen \& K. Sexton-Radek (Eds.), Protecting cbildren from violence: Evidence-based interventions (pp. 1-12). New York, NY: Psychology Press.

Leygue, C., Maio, G. R., Gebauer, J. E., Karremans, J. C., \& Webb, E. (2013). Evidence of aversive childism: Dissociations between explicit and implicit evaluations of children. Unpublished manuscript, Cardiff University.
Ligue Internationale Contre le Racisme et l'Antisémitisme. (2010). 'Your skin color. Shouldn't dictate your future" - Campaign against racism and anti-Semitism. Retrieved from http://www.ufunk. net/en/publicite/contre-le-racisme-et-lantisemitisme/

McArthur, L. Z., \& Apatow, K. (1984). Impressions of baby-faced adults. Social Cognition, 2, 315-342. doi:10.1521/soco.1984.2.4.315

McConnell, A. R., \& Leibold, J. M. (2001). Relations among the Implicit Association Test, discriminatory behavior, and explicit measures of racial attitudes. Journal of Experimental Social Psychology, 37, 435-442. doi:10.1006/jesp.2000.1470

Mitchell, J. P., Nosek, B. A., \& Banaji, M. R. (2003). Contextual variations in implicit evaluation. Journal of Experimental Psychology: General, 132, 455-469. doi:10.1037/0096-3445.132.3.455

National Fair Housing Alliance. (n.d.). How can we tell him that the color of his skin is keeping his family from the home of his dreams? [Race discrimination poster]. Retrieved from http://portal.hud.gov/ hudportal/documents/huddoc?id=13race_ posters_en.pdf

Nosek, B. A., Banaji, M., \& Greenwald, A. G. (2002). Harvesting implicit group attitudes and beliefs from a demonstration web site. Group Dynamics: Theory, Research, and Practice, 6, 101-115. doi:10.1037/1089-2699.6.1.101

Office for National Statistics. (2012). 2011 census: Key statistics for local authorities in England and Wales. Retrieved from http://www.ons. gov.uk/ons/publications/re-reference-tables. $\mathrm{html}$ ?edition $=\mathrm{tcm} \% 3 \mathrm{~A} 77-286262$

Rachel, A. (1989, November 3). JB paradise for foreign beggars. New Straits Times, p. 1. Retrieved from https://news.google.com/newspapers?nid $=\mathrm{x} 8 \mathrm{G}$ 803Bi31IC\&dat $=19891103 \&$ printsec $=$ frontpage $\&$ hl $=$ en

Rudman, L. A., Feinberg, J., \& Fairchild, K. (2002). Minority members' implicit attitudes: Automatic ingroup bias as a function of group status. Social Cognition, 20, 294-320. doi:10.1521/ soco.20.4.294.19908

Stöbel-Richter, Y., Beutel, M. E., Fink, C., \& Brähler, E. (2005). The "wish to have a child," childlessness and infertility in Germany. Human Reproduction, 20, 2850-2857. doi:10.1093/humrep/dei121

UNICEF Ireland. (2011). I will develop [UNICEF campaign]. Retrieved from https://as6882a.files. wordpress.com/2012/02/unicef-develope-2.jpg 